\title{
Article \\ Consumer Sustainable Shopping Practices for Small Business during COVID-19
}

\author{
Sejin $\mathrm{Ha}^{1}{ }^{1}$, Michelle Childs ${ }^{1, * \mathbb{D}}$, Christopher T. Sneed $^{2}$ and Ann Berry ${ }^{2}$ \\ 1 Department of Retail, Hospitality and Tourism Management, The University of Tennessee, \\ Knoxville, TN 37996, USA; sha5@utk.edu \\ 2 Department of Family and Consumer Sciences, The University of Tennessee, Knoxville, TN 37996, USA; \\ csneed@utk.edu (C.T.S.); aaberry@utk.edu (A.B.) \\ * Correspondence: mlchilds@utk.edu; Tel.: +1-865-974-8405
}

Citation: Ha, S.; Childs, M.; Sneed, C.T.; Berry, A. Consumer Sustainable Shopping Practices for Small Business during COVID-19. Sustainability 2021 13, 12451. https://doi.org/10.3390/ su132212451

Academic Editors: Jiyoung Kim, Stacy H. Lee, Gargi Bhaduri and Tae-Im Han

Received: 25 July 2021

Accepted: 5 November 2021

Published: 11 November 2021

Publisher's Note: MDPI stays neutral with regard to jurisdictional claims in published maps and institutional affiliations.

Copyright: (c) 2021 by the authors. Licensee MDPI, Basel, Switzerland. This article is an open access article distributed under the terms and conditions of the Creative Commons Attribution (CC BY) license (https:// creativecommons.org/licenses/by/ $4.0 /)$.

\begin{abstract}
The purpose of this study was to understand the factors that attract consumers to small businesses during the COVID-19 pandemic to assist with small businesses. Factors of interest included emotional (positive and negative) and cognitive experiences (resilience, optimism) during the pandemic and demographic characteristics (gender, generation, education, income, and employment status). Using a convenience survey sample in U.S. $(N=315)$, this study found that positive and negative emotions, active resilience, and demographic characteristics (generation, education, income, and employment status) can explain consumer shopping frequency and number of services used with small businesses during a pandemic. Small businesses may seek to trigger active resilience and emotions (negative and positive) in their marketing/advertising avenues to attract consumers' sustainable consumption practices and may consider pivoting to attract particular consumer segments that are more likely to lend favorable actions toward sustainable consumption.
\end{abstract}

Keywords: COVID-19 consumer behavior; small business; emotions; resilience; optimism; demographics

\section{Introduction}

As COVID-19 spread across United States, small businesses face unprecedented change with significant economic challenges. In fact, in a survey of over 1 million small businesses, researchers found that consumer spending at small businesses was reduced $35 \%$ in the midst of COVID-19, compared with the previous year [1]. Due to this reduction, nearly $40 \%$ of small business owners report that it is unlikely or somewhat unlikely they will still be open at the end of 2020 [2]. Additionally, based on a survey of over 8000 small businesses in late March 2020, nearly 60\% reported they had already laid off a substantial portion of their employees due to COVID-19. These unfortunate results are particularly concerning given that small businesses account for $99.7 \%$ of all businesses [3], thus providing livelihood to a significant workforce in the United States. Business owners and consumers are concerned about changes in consumer behavior and its economic impact, surprisingly, even more than health-related concerns [4]. Consumers' priorities shifted as a result of the pandemic, and new buying behaviors have emerged as a strategy to adjust based on the uncertainty of the pandemic. Particularly, consumers have demonstrated an increased concern for a broader social and ecological system [4,5], with outpours of support for sustainable efforts and well-being of society as consumers adjust to this new economic environment [5]. While it is clear that consumers exhibit behavioral changes in response to the COVID-19 outbreak [6], there is yet no clear understanding of consumption patterns at any point during COVID-19 as it relates to small businesses, particularly at the onset of the pandemic. The current state of the research field is extremely limited. Of the existing studies, consumer behavior research has focused on panic buying, impulsive buying and hoarding [7-9], and the effect of stay-at-home orders on consumer behavior [10]. The conclusions of this research stream are still in their infancy, given the unprecedented nature 
of the pandemic. Especially, no empirical investigation exists into how consumer spending has had an impact on small businesses at the onset of the COVID-19 pandemic.

Therefore, the purpose of this study is to explore consumer response to small businesses, both brick-and-mortar and online businesses, at the beginning of COVID-19. Of particular focus in this study is sustainable consumer practices in response to small businesses at the beginning of COVID-19. Drawing from the notions of sustainability consumption models [11-16], we argue that consumer experiences during the pandemic are likely to affect how they perceive small businesses undergoing the same hardship and thus reflect their shopping behavior. Specifically, we are interested in consumers' psychological experiences with COVID-19 and individual demographics and how they influence shopping frequency and number of services used for small businesses during these initial challenging times.

Based on previous research [2,17], this study focuses on small retail businesses (i.e., operations with fewer than 250 employees) at the onset of the pandemic, since these firms are most likely to be affected by COVID-19 [18], while having meaningful associations with consumers' sustainable consumption practices $[19,20]$. This includes micro (fewer than 10 employees), small (10-49 employees), and medium enterprises (50-249 employees) [21]. Similar to this study, previous research $[2,18]$ has grouped these business classifications for analysis and clear insight on consumer consumption with small business during COVID-19. There exists no empirical research that has identified major consumer characteristics driving shopping behaviors with small retailers during COVID-19, to the best of our knowledge, and thus, we developed research questions instead of research hypotheses for a broad understanding of the phenomenon. The following two research questions are developed:

1. Can shopping frequency and the number of services used for small business at the onset of the COVID-19 pandemic be explained by the consumers' emotional and cognitive experiences (e.g., emotions, resilience, optimism)?

2. Are there any differences in shopping frequency and the number of services used for small business at the onset of the COVID-19 pandemic, depending on their demographic characteristics such as gender, generation, education, and/or employment status?

Understanding customer actions is now more important than ever in order for small business to sustain and thrive during the pandemic. This study makes theoretical contributions to consumer behavior literature in an attempt to contribute to the current state of research during the COVID-19 pandemic and develop conclusions regarding consumer sustainable shopping practices. Additionally, findings of this study provide insightful implications for small businesses to develop healthy business practices; knowledge gained from this study can aid at-risk small businesses in targeting consumers to remain sustainable and thrive during these challenging times for businesses.

\section{Conceptual Background}

\subsection{Impact of Disasters on Small Businesses and Consumer Behavior}

Small businesses are particularly vulnerable to sustainable operations during times of crisis due to a lack of resources (capital and physical assets) when compared with large enterprises [22-25]. This greater pool of financial resources is often reserved as part of a disaster recovery plan for larger companies, whereas small businesses do not necessarily have this luxury [24-26]. According to the US Federal Emergency Management Association (FEMA), $40 \%$ of small businesses have less opportunity to sustain and reopen following a disaster, with an additional $25 \%$ of small business that do reopen closing again within a year following a disaster [27]. This is especially problematic given that small businesses make up the majority of firms within the United States, thus being responsible for significant employment opportunities [21]. As such, it is vital to understand the factors that contribute to survival of small business facing a disaster. In particular, since consumers drive the purchase behaviors of small businesses, it is particularly useful to investigate consumer responses to disasters, precisely related to small business, which can better equip 
small businesses for potential vulnerabilities post-disaster while enhancing sustainable consumer lifestyles.

While research is still limited on the extent to which small businesses are impacted and recover from disasters [24], we do know that the road toward recovery following disasters for small business is full of obstacles and challenges and can threaten the long-term health of the business [28]. Not only do disasters disrupt infrastructure, facilities, and resources [29,30], they also cause trauma and psychological impacts to individuals [28,31], all of which have an impact on the financial outlook of the business. Disasters can leave community residents, including business owners, with life-altering health concerns stemming from an increase in stress, shock, depression, and anxiety [28,31,32].

Overall, consumers are notably fearful of disasters. Recent data demonstrate that Americans are more fearful of natural disasters (e.g., hurricanes, tornados, wildfires, floods) affecting their communities than cyber-attacks or terrorist events [33]. Fear and associated feelings can drive changes in consumer behavior [34-36]. Fear and associated feelings (e.g., anxiety, stress) are likely to activate coping mechanisms, which can be expressed through shopping behaviors [35,37]. While research is limited on the subject, recent research helps to understand the impact of fear from disaster on consumer shopping behavior [35]. In their investigation of consumers impacted by Hurricane Matthew in 2016, for example, researchers found that fear significantly drove purchasing behaviors. In particular, consumers with higher levels of fear of disaster had heightened concerns centered on their shopping trips, which includes waiting in lines, crowded stores, and associated frustrations (i.e., access convenience), paying higher prices, and lack of sales promotions (i.e., transaction convenience) [35]. Despite these fears, consumers still felt more compelled to visit and purchase from stores for essential items and as a mechanism to entertain or de-stress, when compared with pre-disaster shopping behaviors [33]. Likewise, observational purchase data indicate that, in times of disasters, consumers can be frenzied and rush to stores to overstock on essentials such as gas and groceries [38].

\subsection{Impact of COVID-19 on Small Businesses and Consumer Behavior}

While little is known about how consumers are responding to the COVID-19 crisis, preliminary research and anecdotal evidence helps to shed light on COVID-19's impacts on consumer behavior and retail businesses. Consumers have quickly altered their consumption behaviors in response to the pandemic [7-10]. As COVID-19 spread across the United States in spring 2020, consumers were faced with making changes in their households and daily activities, which drastically altered their consumer behaviors. A large number of businesses were closed; for those that were open, consumers experienced disruptions in the supply chain that influenced the availability of goods. Consumers were also seeing changes in the labor force and practicing new health and safety measures, including limiting trips outside their homes [4]. According to a recent survey conducted by the National Retail Federation (NRF), over $90 \%$ of consumers have changed their shopping behaviors in response to COVID-19 [39]. While most Americans still choose to shop in brick-and-mortar stores (vs. online), they are taking extra health and safety precautions while in store, including using disinfectant, altering their shopping times to avoid crowds, limiting cash handing, and seeking self-checkout [40]. A survey of 24,400 consumers across the United States between 16-18 March 2020, revealed that consumers are also stockpiling essential items, such as water, toiletries, cleaning, and pet supplies. Given the urgency of product needs, consumers are losing their brand loyalty, i.e., selecting any in-stock items [40].

These drastic changes in consumer behaviors are confirmed using transaction-level data. In an analysis of consumer spending of 44,600 US consumers, researchers used transaction data to conclude that, as uncertainty in the inability to patronize stores increased, consumers stockpiled household products [6]. In particular, household spending dramatically increased as consumers first became aware of COVID-19 [6,41]. Consumers patronized grocery stores at an increased rate, rather than restaurants [6], and began utilizing food delivery services [1]. Interestingly, researchers note that the speed and 
timing of these trends varied significantly across groups of consumers, depending on their geographic location and government reaction to the outbreak (e.g., shelter-in-place orders) [6]. However, these stay-at-home requests had a negative impact on consumers' travels and spending, causing disruptions to small businesses and retail stores in many industries $[1,18]$.

\subsection{Consumer Shopping Behaviors with Small Business as Sustainable Consumptiton Practices}

This study posits that consumer shopping with a small business reflects consumers' sustainable consumption practices. As for sustainable consumption research, much work has focused on sustainability from the environmentally friendly consumption perspective $[11,12]$. This one-sided conceptualization has been challenged by studies arguing that sustainability goes beyond environmental actions $[13,14]$. Comprehensive models such as Elkington's [15] triple bottom line model, Huang and Rust's [14] model of sustainability consumption, and Lim's [16] model of sustainable consumption explicate sustainable practices around various facets. They included economic/corporate consumption focusing on maximizing benefits for people, business, and society; environmental consumption concerning reducing resource use, conserving resources, and minimizing environmental degradation; and ethical/social-justice-driven consumption prompting equal economic, natural, and social rights and opportunities. The comprehensive approaches to sustainability are well recognized in various consumption contexts that sustainable concerns or mindsets are associated with consumers' willingness to pay for fair-trade product [42], use of sharing economy platforms [43], and purchases from local stores [17]. Taken together, consumers' actions in response to small retailers during the pandemic is, at least in part, considered indicative of a sustainable practice, but little is empirically known about the associations.

To examine consumers' behaviors towards small business, we chose to focus on two variables, shopping frequency and the number of services used with small businesses, for several reasons. First, as highlighted by Lim [16], a key premise of sustainability is mindful consumption, an awareness, attention, and engagement with the present moment, including care towards the self, one's community, and nature. Pertinent to this study, individuals' actions towards supporting community small businesses are fundamental to sustainable practice. When consumers enhance small businesses sustainability through consumption, funds directly benefit their community, individuals, and their own lives to a greater extent than larger firms, thus contributing to the sustainability of the operations of the greater community. Second, shopping frequency and number of services used are common variables that academic researchers have investigated to predict consumers' positive responses to retail businesses such as preference, repurchase intention, and store loyalty [44-46]. Similarly, research also considers the number of services used as a relational outcome variable [47]. That is, capturing individuals' practices in terms of frequency of shopping and utilization of services lends itself to a clear understanding of consumption practices, thus contributing to consumers' positive responses to retail businesses. Third, with the arrival of COVID-19 and its devastating impact on the small business sector, many small businesses are at the greatest risk of disruption and a lack of sustainable operations [2]. In this time of crisis, behavioral forms of consumption (i.e., shopping frequency and number of services used) are of paramount importance for small business survival and provide practical insight for small businesses during this trying time. Therefore, the two variables are deemed indicative of consumers' behavioral actions in support of small retailers, and hence, are the focus in this study. Shopping frequency with small businesses refers to how often consumers shop with the small business in the time of the pandemic. The number of services offered is defined as a count of service options used by a consumer from small businesses (e.g., online order and delivery, online order and pickup, gift card purchases, donations to stores, donations to employees, and coupon codes) [47].

In response to a snapshot of consumer behavior during the COVID-19 pandemic, small businesses must consider how, when, and where they sell their products to remain sustain- 
able during times of crisis. However, what is yet to be understood is which consumers are likely to patronize small businesses so that owners and managers can better attract current customers for sustainable business operations. Particularly, during these trying times, small businesses would benefit from a clear understanding of what consumers may be experiencing (i.e., emotions, resilience, optimism) and who to target (i.e., by generational category, employment status, income). By segmenting customers in this fashion, small businesses can be better equipped to target customers while experiencing limited resources.

\subsection{Consumers' Psychological Responses to Disasters}

This study examines consumers' psychological responses to COVID-19 in terms of emotions, resilience, and optimism. During the pandemic, consumers may experience feelings ranging from negative (e.g., feeling fearful) to positive feelings (e.g., feeling calm or hopeful about new normalcy after the pandemic). Resilience reflects consumers' efforts to restore or maintain internal or external equilibrium from their stressful conditions, such as COVID-19 [48]; optimism reflects consumers' expectations and thoughts that there will be a positive future after COVID-19.

Research on consumer responses to natural disasters demonstrate that individual factors reflect differences in emotional responses that allow individuals to cope with such traumatic events [49]. Coping, referring to how individuals prevent and overcome stress [50], can be managed through one's emotional responses [51]. Emotion-focused coping mechanisms can be triggered to control internal emotions, in the event that external situations are out of one's control. In terms of disasters, individuals may not be able to solve external (e.g., physical impact) issues; as such, emotional coping strategies are carried out to cope with, manage, and control stress induced from such stressful events [52]. In disaster literature, researchers have predominately focused on the influence of negative emotions (e.g., anger, anxiety, sadness) in coping with crisis [53-55]. An understanding of negative emotional responses to disasters can shed light on adverse outcomes to share with stakeholders, but it does little to overcome an individual's stress induced from crisis.

While less developed, a growing body of research has worked to identify positive psychological responses to individuals' crisis coping. A critical positive psychological response to disaster is resilience, i.e., the adaptive capabilities of individuals [56]. Resilient individuals apply a variety of adaptive behaviors to cope with stress to overcome challenging events or threatening circumstances [57]. Resiliency is an ongoing practice and includes attitudes, beliefs, and physical functions [58]. Along these lines, consumers' level of optimism can play a strong role in how consumers respond to disaster. Optimism, i.e., the generalized expectancy for positive outcomes [59], is associated with positive responses and performance, despite difficult situations [60]. Consumers' optimism generates more positive beliefs about future economic conditions [61], which will likely have an impact on purchase behavior. Despite the likelihood that positive emotional responses can trigger unique outcomes in consumer behaviors in times of disaster, little research has been conducted on the topic. Such understanding will be useful to help sustain small business, which may experience interruptions in shopping behavior in times of disasters. In line with previous research [62], since there is no empirical evidence identifying which and how consumers' psychological, emotional, and cognitive experiences affect their behaviors during a pandemic, we developed the following research question instead of a research hypothesis:

RQ 1. Can shopping frequency and number of services used for small businesses sustainability at the onset of the COVID-19 pandemic be partially explained by the consumers' emotional and cognitive (resilience and optimism) experiences during the pandemic?

\subsection{Demographics in Relation to Disasters}

This research explores differential responses to shopping frequency and the number of services used with small businesses during a pandemic based on demographic characteristics. While research in this critical area lacks deep exploration, the literature does indicate that responses to disasters vary across gender, age, education, and employment 
status [63]. For example, a densely explored area within disaster management focuses on gender and levels of resilience, i.e., an individual's ability to cope with risk, adversity, and stress [63-65]. Overall, studies indicate that females have greater propensity to be impacted by disasters; females are also more likely to experience greater adverse effects and report lower levels of resilience following disasters [63]. While researchers do recognize this consistent effect, as shown in the literature, it may be attributed to wider issues centered on females' social transformations and the depletion of resources related to caregiving [66,67]; more research is still needed to assess differential burdens of disasters by gender [68].

Furthermore, researchers have generally agreed that age (including generation) dictates differential responses to disaster, but findings have yet to agree on the age range that aids consumer responses following disaster $[63,69]$. For instance, in their research investigating resilience post-disaster, Bonanno et al. [63] reported that older consumers (i.e., 65 years and older) have higher levels of resilience when compared with younger consumers (i.e., 18-24 years old). However, some research reports that even older individuals (i.e., $75+$ ) exhibit greater resilience in the long-term compared with participants slightly younger (i.e., 65-74 years old) [54]. Interestingly, researchers also found that, when faced with stressors induced by the global pandemic, age is positively correlated with resilience [70,71]. However, despite the understanding that age is related to the degree in which individuals respond to disasters, less is understood about consumer action taken in response to disaster.

Additionally, the literature points to the notion that education level and employment status have an influence on consumers' level of resilience [63,67]. In terms of education, Bonanno et al. [63] found that, post-disaster, participants with a college education were half as likely to be resilient when compared with those with less than a high school degree. In this case, education appears to impede resilience following a disaster. On the other hand, emphasizing education (particularly disaster-related education) is vital to manage posttraumatic stress and anxiety following a disaster [72]. However, researchers tend to agree that employment status has a profound effect on disaster response. Overall, job opportunities, job growth, and consistent income stemming from employment are found to increase consumer resilience in the aftermath of a disaster [63,73].

Overall, while some research has studied the influence of demographic characteristics as it relates to disaster responses, much research has included information on consumer resilience level. While this understanding has importance, it provides a significant limitation given that a few studies explore the associations between consumer demographics and their responses to small business affected by disaster. Since there is no empirical evidence identifying which and how consumer demographics affect consumers' patronage behavior in support of small business during the pandemic to our best knowledge, the following research question is proposed:

$\mathrm{RQ} 2$. Are there any differences in the shopping frequency and the number of services used for small businesses' sustainability at the onset of the COVID-19 pandemic depending on their demographic characteristics such as gender, generation, education, income, and/or employment status?

\section{Method}

\subsection{Sample and Data Collection}

The study population consisted of consumers over 18 years old who resided in the United States in the time of COVID-19. Data were collected at the onset of the COVID-19 pandemic in March 2020, and a total of 315 consumers who participated in a consumer panel of a survey sampling provider (Qualtrics) completed an online survey of shopping behavior related to COVID-19. Convenience sampling was used to collect data, so data are not representative of the United States' population. However, researchers took several steps to work towards a more representative sample. First, researchers requested that quotas be implemented to reflect demographic characteristics (i.e., gender and income) of the general United States population. Zip code information was also collected in the 
survey to identity respondents' location. Additionally, a filter question was used, "When did you first start to modify, if at all, your shopping and purchase behavior for COVID-19". To align with the purpose of this study, respondents who reported not modifying their shopping or purchase behavior for COVID-19 did not quality for this study and were unable to participate. As a result of screening protocol, a total of 1664 individuals initiated the survey, but only 315 consumers qualified for completion.

For respondents that qualified for the study, the survey proceeded in three phases. After reading a brief introduction about the research, additional information was collected regarding any extra money spent due to the pandemic: "How much extra money did you spend on products during the pandemic?". Following this, respondents evaluated questions on emotional and psychological experiences they experienced at the onset of the pandemic and questions related to shopping behaviors with small businesses. The definition of small business was provided as "small, independent or family-owned business". Lastly, demographic information was collected.

\subsection{Measures}

The questionnaire included self-report measures of emotions, resilience, experiences of optimism during COVID-19, and small-business-related questions. Emotional experience was captured using an eight-item scale from Maheswaran and Meyers-Levy [74] on a fivepoint scale ( 1 = not at all; 5 = extremely) (e.g., "Currently to what extent do you experience fearfulness?"). Smith et al.'s [75] brief resilience scale (BRS), developed to measure the ability to recover from difficult circumstance, was modified and used to assess resilience (e.g., When thinking about your typical behavior: "I tend to bounce back quickly after hard times"). Optimism was assessed using Taute et al.'s [76] optimistic utilization of emotions scale, which consisted of six items (e.g., When thinking about your typical behavior: "I keep trying in the face of obstacles"). Resilience and optimism were rated on a 7-point scale $(1=$ strongly disagree; $7=$ strongly agree). Higher scores reflect higher resilience and optimism.

Consumers' sustainable shopping practices for small business were operationalized in two ways: shopping frequency and the number of services used with small businesses. Shopping frequency with small businesses was measured using a single item (i.e., "How often have you shopped with small businesses in the past week?") on a 7-point scale ( 1 = I haven't bought from a small business; $7=$ over 5 times). We then provided a list of six services offered by small businesses (i.e., online order and delivery, online order and pickup, gift card purchases, donation to store, donation to employees, and coupon codes) and asked respondents to indicate all service options they have practiced with small businesses, both brick-and-mortar and online businesses, during the pandemic $(0=$ no, $1=$ yes $)$. Following the method used in previous research [46], the number of services used with small business was computed by counting the number of uses of different types of services respondents reported, resulting in scores ranging from 0 to 6 . Higher scores indicate a higher level of shopping frequency and number of services used for small business.

For demographic information, age, gender, ethnicity, education, and employment status were obtained. Based on age, generation was coded as a categorical variable with three levels ( 1 = Millennial; 2 = GenX; 3 = Baby Boomer).

\subsection{Statistical Analyses}

Considering that the features of optimism, resilience, and emotions may vary by situations (i.e., the pandemic), we first discovered the factor structure inherent to the measure of each variable using exploratory factor analysis (EFA). Then, confirmatory factor analysis (CFA) was tested to confirm the measurement model obtained from the EFA. To do so, we split the data randomly into two datasets and ran the analyses with different data sets to avoid capitalization on chance. The EFA $(n=148)$ of each scale was rotated using a maximum likelihood and an oblimin rotation method. Items that showed poor psychometric properties ( $<0.30$ communality, $<0.40$ factor loading, or $>0.20$ cross-loading) were 
eliminated. Two criteria (eigenvalue of 1.0 or above and the scree plot) were applied for the factor number decision. In addition, Cronbach's alphas were computed to test internal consistency. Next, CFA $(n=167)$ was carried out to assess properties of the measurement model, including composite reliability and convergent and discriminant validity. After establishing a well-fitted measurement model, we ran multiple regression analysis and one-way ANOVA with a combined data set to answer RQ1 and RQ2, respectively.

\subsection{Sample Characteristics}

We assessed whether data were susceptible to geographic regions in two ways. First, using zip codes as proxies of respondents' current residency, we compared the geographic spread of respondents with community demographic data from the 2019 United States Census Bureau American Community Survey, in which aggregate population estimates by zip codes were provided [48]. The comparison indicated somewhat similar proportions in populations by geographic regions between the study population and US population groups (\% of population living in areas with zip codes starting with $0=6.35 \% \mathrm{vs} .7 .53 \%$, $1=12.70 \%$ vs. $10.39 \%, 2=9.84 \%$ vs. $10.13 \%, 3=18.10 \%$ vs. $13.70 \%, 4=7.30 \%$ vs. $10.44 \%$, $5=3.81 \%$ vs. $5.35 \%, 6=8.89 \%$ vs. $7.61 \%, 7=10.16 \%$ vs. $11.77 \%, 8=5.40 \%$ vs. $6.83 \%$, $9=17.46 \%$ vs. $16.16 \%$ ). Next, ANOVA was performed to test whether the respondents' emotional and cognitive experiences and demographic characteristics were different by geographical regions. Results showed no significant differences across different geographic regions in optimism $(F=1.07, p=0.39)$, resilience $(F=0.79, p=0.68)$, age $(F=0.74, p=0.63)$, affect $(F=0.74, p=0.68)$, gender $(F=0.99, p=0.45)$, and income $(F=0.90, p=0.45)$. Upon analyses of this data, we can conclude that despite the non-probability sampling technique applied, the respondents' geographical regions did not affect the results of this study.

In terms of demographics and respondents' shopping characteristics (Table 1), the sample consisted of $50.5 \%$ female $(n=159)$ and $48.9 \%$ male $(n=154)$ respondents with an average age of 45 . Most were Caucasian (74\%) and well-educated, with $46.3 \%$ reporting a college degree or higher. Household income varied in all categories. Approximately 38.6\% of respondents reported annual income less than USD 40,000, 49.8\% between USD 40,000 and USD 100,000, and 21.6\% greater than USD 100,000. The majority of respondents started to modify their shopping behaviour more than a month ago $(n=202 ; 64.10 \%)$ and varied widely in how much money they spent in their preparation.

Table 1. Sample characteristics.

\begin{tabular}{cccc}
\hline Variables & $N$ & Mean or $\%$ & Standard Deviation \\
\hline Age (in years) & 315 & 44.71 & 17.23 \\
\hline Gender & & & \\
Male & 154 & $48.90 \%$ & \\
Female & 159 & $50.50 \%$ & $0.60 \%$ \\
Others & 2 & \\
Ethnicity & & & \\
White & 233 & $84.00 \%$ \\
African American & 28 & $7.90 \%$ \\
Hispanic & 23 & $7.30 \%$ \\
Asian American/Asian & 23 & $2.60 \%$ \\
Others & 8 & \\
Education & & \\
Less than high school degree & 9 & $2.90 \%$ \\
High school graduate & 53 & $16.80 \%$ \\
Some college & 107 & $34.00 \%$ \\
College degree & 90 & $28.60 \%$ \\
\hline
\end{tabular}


Table 1. Cont.

\begin{tabular}{|c|c|c|c|}
\hline Variables & $N$ & Mean or \% & Standard Deviation \\
\hline \multicolumn{4}{|l|}{ Annual household income } \\
\hline$\leq \mathrm{USD} 19,999$ & 39 & $12.40 \%$ & \\
\hline USD 20,000-USD 39,999 & 61 & $16.20 \%$ & \\
\hline USD 40,000-USD 59,999 & 67 & $21.30 \%$ & \\
\hline USD 60,000-USD 79,999 & 52 & $16.50 \%$ & \\
\hline USD 80,000-USD 99,999 & 38 & $12.00 \%$ & \\
\hline$\geq$ USD 100,000 & 68 & $21.60 \%$ & \\
\hline \multicolumn{4}{|c|}{ When did you first start to modify your shopping? } \\
\hline More than a month ago & 202 & $64.10 \%$ & \\
\hline $2-4$ weeks ago & 89 & $28.30 \%$ & \\
\hline $1-2$ weeks ago & 16 & $5.10 \%$ & \\
\hline in the past week & 8 & $2.50 \%$ & \\
\hline \multicolumn{4}{|c|}{ Extra money you spent on products } \\
\hline USD 0 & 73 & $23.20 \%$ & \\
\hline$<$ USD 100 & 71 & $22.50 \%$ & \\
\hline USD 100-USD 199 & 49 & $15.60 \%$ & \\
\hline USD 200-USD 299 & 56 & $17.80 \%$ & \\
\hline USD 300-USD 399 & 31 & $9.80 \%$ & \\
\hline USD 400-USD 499 & 10 & $3.20 \%$ & \\
\hline$\geq$ USD 500 & 25 & $7.90 \%$ & \\
\hline
\end{tabular}

\section{Results}

The research variables included emotions, resilience, and experiences of optimism during COVID-19. Table 2 presents the measurements of the variables. The EFA revealed that optimism emerged as a unidimensional construct (total variance $=63.37 \%$ ), but resilience and emotion turned out to be two-dimensional constructs (Table 2). Resilience was shown to present active and passive forms of resilience in relation to COVID-19, which together explained $70.72 \%$ of the total variance in the original variable; active resilience represented an individual's ability to proactively adjust to disturbances (e.g., "I tend to take a long time to get over setbacks in my life"), and passive resilience highlighted an individual's resistance to and withstanding stressful situations ("It is hard for me to snap back when something bad happens"). The two-dimensionality of resilience was inconsistent with Smith et al.'s [75] finding that the resilience scale was unidimensional. However, there exist studies that identified resilience to be multifaceted (e.g., active and passive resilience) [76], and the results suggests that during COVID-19, consumers face this time of uncertainty with active and passive resilience. Next, emotions were shown to encompass negative (e.g., "tense") and positive (e.g., "relaxed") affective states, which together explained 75.76\% of the total variance in the original variable. That is, consumers experienced negative as well as positive emotions during the COVID-19 pandemic.

The CFA was used to evaluate a measurement model of the 20 items, including the 5 latent constructs' scales. The result showed an acceptable fit of the model to the data: $\chi^{2}=305.98 ; d f=160 ; \chi^{2} / d f=1.91$; standardized $\mathrm{RMR}=0.056$; IFI $=0.94 ; \mathrm{TLI}=0.93$; CFI $=0.94$; RMSEA $=0.08$ (90\% CI: 0.06, 0.09) [77]. As presented in Tables 2 and 3 , the measurement model demonstrates support for internal reliability, convergent validity, and discriminant validity. Convergent validity was confirmed, as all factor loadings were significant, and the average variance extracted (AVE) of the indicators by their corresponding construct exceeded 0.50 . The composite reliability was greater than 0.88 , confirming the internal consistency of all constructs. In addition, the AVE estimate of each construct was greater than the squared multiple correlation estimates between all possible pairs of constructs, thus confirming the discriminant validity. 
Table 2. Exploratory factor analysis and confirmatory factor analysis.

\begin{tabular}{|c|c|c|}
\hline \multirow[b]{2}{*}{ Factor/Items } & \multicolumn{2}{|c|}{ Std. Factor Loading } \\
\hline & EFA & CFA \\
\hline \multicolumn{3}{|l|}{ Optimism (Var. $=63.36 \%, \alpha=0.91, C R=0.92)$} \\
\hline I keep trying in the face of obstacles & 0.91 & 0.84 \\
\hline I keep going in the face of adversity & 0.90 & 0.83 \\
\hline I never give up when faced with a challenge & 0.79 & 0.81 \\
\hline I continue to try even when it seems hopeless & 0.73 & 0.79 \\
\hline I have the will to win & 0.72 & 0.75 \\
\hline I don't let anxiety keep me from accomplishing my goals & 0.71 & 0.75 \\
\hline \multicolumn{3}{|l|}{$\begin{array}{c}\text { Passive resilience (Var. }=51.24 \%, \alpha=0.88, C R=0.87, \text { reverse } \\
\text { coded for analysis) }\end{array}$} \\
\hline I tend to take a long time to get over setbacks in my life & 0.90 & 0.74 \\
\hline It is hard for me to snap back when something bad happens & 0.83 & 0.90 \\
\hline I have a hard time making it through stressful times & 0.79 & 0.89 \\
\hline \multicolumn{3}{|l|}{ Active resilience $($ Var. $=19.48 \%, \alpha=0.87, C R=0.88)$} \\
\hline I tend to bounce back quickly after hard times & 0.86 & 0.84 \\
\hline It does not take me long to recover from a stressful event & 0.86 & 0.84 \\
\hline I usually come through difficult times with little trouble & 0.79 & 0.80 \\
\hline \multicolumn{3}{|l|}{ Negative emotion $($ Var. $=52.53 \%, \alpha=0.95, C R=0.90)$} \\
\hline Anxious & 0.93 & 0.90 \\
\hline Nervous & 0.92 & 0.89 \\
\hline Tense & 0.90 & 0.90 \\
\hline Fearful & 0.85 & 0.82 \\
\hline Stressed & 0.82 & 0.86 \\
\hline \multicolumn{3}{|l|}{ Positive emotion $($ Var. $=23.23 \%, \alpha=0.87, C R=0.88)$} \\
\hline Relaxed & 0.93 & 0.71 \\
\hline Comfortable & 0.83 & 0.92 \\
\hline Reassured & 0.74 & 0.87 \\
\hline
\end{tabular}

Note: Var. = variance explained, $C R=$ composite reliability.

Table 3. Convergent and discriminant validity.

\begin{tabular}{cccccccc}
\hline & Mean & SD & (1) & (2) & (3) & (4) & (5) \\
\hline (1) Optimism & 5.31 & 1.05 & 0.70 & 0.06 & 0.43 & 0.02 & 0.13 \\
\hline (2) Passive resilience & 4.22 & 1.53 & & 0.70 & 0.27 & 0.34 & 0.04 \\
\hline (3) Active resilience & 4.46 & 1.37 & & & 0.70 & 0.05 & 0.25 \\
\hline (4) Negative emotion & 2.80 & 1.15 & & & & 0.74 & 0.11 \\
\hline (5) Positive emotion & 2.62 & 1.02 & & & & & 0.71 \\
\hline
\end{tabular}

Note: Numbers in the diagonal are the average variance extracted by each construct. Numbers above the diagonal show the squared correlation coefficients between the constructs.

RQ1 asked whether or not shopping frequency and the number of services used for small business at the onset of the COVID-19 pandemic would be associated with consumers psychological experiences, that is, passive and active resilience, optimism, and the negative and positive emotions experienced. Two multiple regression models were formulated and tested for the two dependent variables: shopping frequency with small business and the number of services respondents practiced with small businesses during the pandemic. A tolerance of less than 0.20 and a variance inflation factor (VIF) of 10 or above indicate a multicollinearity concern [78]. The variables did not exhibit serious multicollinearity issues with tolerance estimates between 0.50 and 0.80 and VIF between 1.0 and 2.0.

Table 4 presents the results regarding RQ1. The models for shopping frequency with small businesses $\left(R^{2}=0.12 ; F=8.34 ; p<0.001\right)$ and for all services in use $\left(R^{2}=0.04 ; F=2.64\right.$; $p=0.024)$ were significant and showed acceptable goodness of fit. Shopping frequency 
with small businesses in the time of the pandemic was significantly and positively predicted by active resilience, positive emotion, and negative emotion experienced during the challenging time but not by optimism and passive resilience. That is, the stronger consumers experienced active resilience, positive emotion, and negative emotion with the pandemic, the more often they shopped at small businesses. On the other hand, the number of services consumers used with small business is predicted by active resilience only. That is, the higher consumers' active resilience during the difficult time, the more services they enjoyed from small businesses. In all, active resilience was a critical factor predicting both aspects of shopping behaviors with small business through the pandemic, whereas positive and negative emotions had significant impacts on shopping frequency with small businesses only. However, neither optimism nor passive resilience played a role in predicting shopping frequency and the number of services used for shopping with small business.

Table 4. Regressions predicting consumer shopping with small business during a pandemic.

\begin{tabular}{|c|c|c|c|c|}
\hline & \multicolumn{2}{|c|}{ Shopping Frequency } & \multicolumn{2}{|c|}{ Number of Services Used } \\
\hline & Std. Beta & $t$-Value & Std. Beta & $t$-Value \\
\hline \multicolumn{5}{|l|}{ Independent Variables } \\
\hline Optimism & $<0.01$ & $0.02^{\mathrm{ns}}$ & 0.00 & $0.05^{\mathrm{ns}}$ \\
\hline Passive resilience & -0.01 & $-0.09 \mathrm{~ns}$ & 0.01 & $0.13^{\mathrm{ns}}$ \\
\hline Active resilience & 0.21 & $2.93^{* *}$ & 0.15 & $1.92 *$ \\
\hline Negative emotion & 0.28 & $4.14^{* * *}$ & 0.08 & $1.12^{\mathrm{ns}}$ \\
\hline Positive emotion & 0.14 & $2.31 *$ & 0.10 & $1.55^{\mathrm{ns}}$ \\
\hline$F$-value & 8.34 & & 2.64 & \\
\hline$R^{2}$ & 0.12 & & 0.04 & \\
\hline
\end{tabular}

Note. ${ }^{*} p<0.05,{ }^{* *} p<0.01,{ }^{* * *} p<0.001 ;$ ns $=$ non-significant relationship.

RQ2 asked if there were differences in the shopping frequency and the number of services used with small businesses at the onset of the COVID-19 pandemic depending on demographic characteristics such as gender, generation, education, income, and employment status. A One-way ANOVA followed by a post-hoc Tukey test were used for the comparisons of the subgroups of each demographic trait. For generation, a new variable of generational cohort with three subgroups, i.e., Millennial, GenX, and Baby Boomer, was created based on age. As presented in Table 5, generation, education, and employment status had significant effects on both aspects of sustainable consumption in support of small business during the COVID-19 pandemic. Conversely, annual household income had an effect on shopping frequency but not on the number of services practiced, whereas neither of them was detected by gender.

Post-hoc Tukey tests revealed that during the pandemic, Baby Boomers shopped less frequently than Millennials $(p<0.001)$ and Generation X $(p<0.001)$; furthermore, Baby Boomers used less services available from small businesses than Millennials $(p=0.022)$. For education, only one pair between high school graduates and postgraduate degree showed a significant difference in that postgraduate degree holders shop more frequently $(p=0.008)$ than high school graduates and use more services than high school graduates $(p=0.021)$ and those with some college education $(p=0.018)$. As for annual household income, affluent respondents with an annual household income of USD 100,000 or higher shopped more frequently than two groups, which are those who make between USD 40,000 and USD 59,999 ( $p=0.03)$ and between USD 80,000 and USD 99,999 $(p=0.018)$; however, the number of services used at small businesses did not differ across different levels of annual household income. Last, retirees shop less frequently than paid workers $(p=0.018)$ and use less services available at small businesses than three subgroups, including paid employees $(p=0.044)$, the self-employed $(p=0.06)$, and those looking for work $(p=0.028)$. In addition, self-employed people shopped more at small businesses than those looking for a job $(p=0.021)$. 
Table 5. ANOVA results.

\begin{tabular}{|c|c|c|c|c|}
\hline \multirow[b]{2}{*}{ Variables } & \multicolumn{2}{|c|}{ Shopping Frequency } & \multicolumn{2}{|c|}{ Services Used } \\
\hline & Mean & $F$ & Mean & $F$ \\
\hline Gender & & & & \\
\hline Female $(n=154)$ & $3.40(1.54)$ & $1.48^{\mathrm{ns}}$ & $1.54(0.83)$ & $0.39 \mathrm{~ns}$ \\
\hline Male $(n=159)$ & $3.58(1.54)$ & & $1.53(0.90)$ & \\
\hline Generation & & $7.94^{* * *}$ & & $3.97 *$ \\
\hline Millennial $(n=92)$ & $3.60(1.51)$ & & $1.68(1.03)$ & \\
\hline $\operatorname{Gen} X(n=83)$ & $3.89(1.63)$ & & $1.61(0.92)$ & \\
\hline Baby Boomer $(n=99)$ & $3.04(1.29)$ & & $1.34(0.68)$ & \\
\hline Education & & $3.02 *$ & & $3.20 *$ \\
\hline Less than high school degree $(n=9)$ & $3.78(1.72)$ & & $1.33(0.50)$ & \\
\hline High school graduate $(n=53)$ & $3.04(1.26)$ & & $1.40(0.69)$ & \\
\hline Some college $(n=78)$ & $3.47(1.56)$ & & $1.46(0.72)$ & \\
\hline College degree $(n=119)$ & $3.40(1.44)$ & & $1.50(0.80)$ & \\
\hline Postgraduate degree $(n=56)$ & $4.02(1.76)$ & & $1.89(1.26)$ & \\
\hline Annual income & & $3.51^{* *}$ & & $2.23^{\mathrm{ns}}$ \\
\hline$\leq \mathrm{USD} 19,999(n=39)$ & $3.54(1.92)$ & & $1.36(0.63)$ & \\
\hline USD 20,000-USD 39,999 $(n=53)$ & $3.51(1.42)$ & & $1.59(1.02)$ & \\
\hline USD 40,000-USD 59,999 $(n=67)$ & $3.12(1.34)$ & & $1.45(0.68)$ & \\
\hline USD 60,000-USD 79,999 $(n=52)$ & $3.37(1.34)$ & & $1.38(0.66)$ & \\
\hline USD 80,000-USD 99,999 $(n=38)$ & $3.11(1.66)$ & & $1.50(0.89)$ & \\
\hline$\geq \operatorname{USD} 100,000(n=68)$ & $4.09(1.54)$ & & $1.81(1.07)$ & \\
\hline Employment status & & $2.26 *$ & & $3.96 * * *$ \\
\hline Working (paid employee, $n=124$ ) & $3.73(1.61)$ & & $1.65(0.93)$ & \\
\hline Working (self-employed, $n=39$ ) & $3.85(1.58)$ & & $1.87(1.24)$ & \\
\hline Not working (temporary laid off, $n=25$ ) & $3.24(1.51)$ & & $1.88(0.78)$ & \\
\hline Not working (looking for work, $n=33$ ) & $3.48(1.44)$ & & $1.21(0.42)$ & \\
\hline Not working (retired, $n=54$ ) & $2.89(1.14)$ & & $1.22(0.54)$ & \\
\hline Not working (disabled, $n=13$ ) & $3.62(1.56)$ & & $1.31(0.85)$ & \\
\hline Not working (other, $n=24$ ) & $3.25(1.78)$ & & $1.33(0.48)$ & \\
\hline
\end{tabular}

Note. ${ }^{*} p<0.05,{ }^{* *} p<0.01,{ }^{* * *} p<0.001 ; n=$ the total number of individuals in the sample; ns $=$ non-significant relationship.

\section{Discussion and Conclusions}

The coronavirus outbreak (i.e., COVID-19) that swept across numerous countries, including the United States [79], subsequently impacted consumer behavior [80] and small businesses. In response to the pandemic, the US Department of Health and Human Services/Centers for Disease Control and Prevention (CDC) regulated temporary business closures, which had a severe impact on the sustainable operations of small businesses. Arising from these events, there were burdens placed particularly on small businesses at the onset of the pandemic, which tend to be concentrated within the retail and services sectors and are the most impacted financially [18]. While consumers demonstrated an increased concern for the social and ecological system through support for sustainable efforts and well-being of society [4,5], statistics demonstrated that small businesses still struggled to remain open and sustain their operations; recent research reports that nearly $40 \%$ of small businesses are pessimistic about their ability to stay open beyond 2020 [2] This is likely due to dramatic changes in consumer behavior and overall reductions in consumer spending [1,4], thus providing an understanding of the factors that can aid consumers' supportive actions for small business at the onset of the pandemic and identifying the specific characteristics (i.e., emotional and cognitive experiences, demographics) of supporters or non-supporters of their business operations.

To more precisely understand consumer factors that have an impact on their shopping behaviors with small business (i.e., small business shopping frequency and number of services utilized) at the onset of the pandemic, this study was interested in testing consumers' psychological experiences related to COVID-19, along with demographic characteristics. This is one of the few studies (e.g., $[1,6-9,18,41,80,81]$ ) that contribute to understanding consumer behavior at the start of the pandemic. Given the notion that consumer behavior 
practices may endure beyond the pandemic crisis [39], this understanding is an essential initial step for both theory and practice.

Overall, our findings help to address problems identified above that have been facing small businesses as a result of COVID-19 by empirically examining factors that may help or hinder shopping frequency and the number of services used for small business operations during this initial challenging time. Given that consumer behavior literature is scarce in relation to COVID-19, researchers investigated these issues in light of crisis management literature. Aligning with this stream of research, our findings contribute to a theoretical understanding regarding how individuals last through a disaster and how it determines their level of coping and overall reactions to the disaster itself and related parties, e.g., small businesses [52-55].

Contributing to an expansive and comprehensive view of sustainability [16], this study adds to previous sustainability literature conceptualizing sustainability going beyond the environmentally friendly consumption perspective [11,12]. Taking the approach that consumers can contribute to small or local businesses is related to mindful practices to patronize small businesses, this study theoretically enhances Lim's [16] proposed premise that sustainability includes mindful consumption practices. As literature emphasizes the need to expand our approach to understanding sustainability $[13,14]$, this study provides evidence of the importance of shopping with small businesses as a sustainable practice.

Our first RQ was concerned with understanding how sustainable shopping practices in favor of small business at the onset of the pandemic can be explained by consumers' emotional and cognitive (resilience and optimism) experiences, helping to address the overall concerns centered on small business survival during these times. Interestingly, results indicated consumers who were actively resilient during the pandemic (i.e., able to bounce back quickly after a stressful event) were more likely to frequent small businesses and used services provided, thus contributing to small business survival. While this is a new contribution to the literature, the findings are in line with characteristics of adaptive individuals [56]. That is, resilient individuals apply adaptive behaviors that allow them to cope with stressful events that are beyond their physical control [75]. To promote resilience in benefiting small businesses during COVID-19, research has emphasized the value of support and social networks when dealing with the aftermath of disaster [81]. That is, individuals can build meaningful levels of resilience when involved in a social network of support.

These findings hold practical implications for small business operators. Emerging variants of COVID-19 have helped to fuel increased case counts, demonstrating that the pandemic is far from finished. As COVID-19 continues to grip communities, small business operators will have the continued opportunity to utilize findings from this study to help inform their business practices. To establish feelings of support and build active resilience, small businesses should brainstorm creative strategies to socialize and provide support during the pandemic. For example, a retailer who sells knitting accessories may hold outdoor socially distanced knitting circles, so that patrons can feel connected and have the chance to remain social and gain support. Perhaps hardware retailers may hold virtual "how-to" sessions with new products for new and loyal consumers. Food service retailers may wish to promote and participate in food drives for local food pantries. Such efforts could demonstrate the retailer's support for the larger community while fostering the resiliency of community members impacted by the pandemic.

Additionally, findings show that consumers' emotional responses (positive and negative) at the onset of the COVID-19 pandemic had an impact on shopping frequency with small business. That is, when consumers have positive (e.g., being reassured or hopeful about new normalcy) or negative (e.g., feeling fearful, stressed) emotional responses as a result of COVID-19, they respond through action to aid small business. This finding helps to address issues for small business created as a result of the pandemic. In this case, small business frequency could be a form of coping with a traumatic event [49], which is managed as an emotional response [51]. Since previous literature has focused on a single aspect 
of emotion related to disasters, such as positive [53-55] or negative [71] emotions, our findings contribute toward understanding a spectrum of emotional responses to disaster by including both positive and negative emotions and demonstrating their roles in consumer shopping behaviors during the pandemic. In addition, the results are in line with findings from recent research that signify the role of negative emotions and positive emotion regulation in quality of life during lockdown [82]. Encouragingly, positive and negative emotional responses significantly predict small business frequency during COVID-19. Sustainability during uncertain times is a critical challenge facing small business owners. The results from this study hold promise and offer pathways by which small business owners can enhance the sustainability of their operations. During these uncertain times, small business owners can help to foster consumers' emotions through pandemic-specific advertising messages. Such messaging could be used through web or social media channels. Small business owners must continually evaluate their pandemic-specific messaging making certain that their messages are tailored to their consumers and that such messaging is helping to increasing patronage and support.

Contrary to previous literature [59-61], optimism (i.e., persistence in the face of adversity, the will to win) and passive resilience (i.e., lengthy setbacks) did not motivate small business consumption during the pandemic. While consumer confidence is currently low in the marketplace as a result of COVID-19 [81,83], business responsibility toward consumers has taken on new significance. The notion that optimism or passive resilience does not move consumers towards small business may pose an enormous challenge, particularly given that small businesses tend to struggle to stay open during this time. Small businesses need to seek to build trust with consumers to encourage a sense of winning and overcoming setbacks to enhance business performance. For instance, small businesses may post vaccine information on their social media sites to generate feelings of victory or conquering current troubles.

Another surprising finding was that, with the exception of active resilience, consumer utilization of small business services at the onset of the pandemic was not explained by their current emotional (positive and negative) and cognitive (passive resilience and optimism) experiences. While this finding proved contrary to our expectations, perhaps the timing of the data collection can explain the insignificant findings. Data were collected at the relative onset of the pandemic and perhaps over time consumers became gradually more comfortable with utilizing services offered by small businesses as part of their sustainable shopping behavior. This may have an impact on the results and additional longitudinal research is needed to help explain findings.

Our second RQ was concerned with understanding how consumer shopping behaviors with small business during the pandemic can be explained by demographic characteristics (i.e., gender, generation, education, income, and/or employment status). Surprisingly and contrary to the thought that females have a greater propensity to be impacted by disaster [63], no gender differences were seen in consumption patterns for small businesses' sustainability during the pandemic. This result is encouraging for small businesses that may be gender oriented.

While the research regarding age/generation and responses to disaster were previously inconsistent in the literature [63,69], our results contribute to more recent literature investigating the relationship between age and responses to the global pandemic [70,71]. This study found that Baby Boomers shop significantly less frequently during the pandemic at small businesses than Millennials and Generation X and use less services offered by small businesses compared with Millennials. This finding does offer guidance to small business owners wishing to sustain the support of Baby Boomers. Given that many Baby Boomers are likely to be retired and on a fixed income, it is important for small businesses targeting this audience to offer value for the money during the course of COVID-19. Perhaps small businesses can offer free additional services (e.g., product installment with purchase, product delivery, web-based personal shopping services) when targeting Baby Boomers over the course of the pandemic. Small businesses may also seek to shift assortments and 
promote their services offered to a younger audience, which is more likely to patronize and contribute to sustaining their business at this time. The creative approaches implemented by small business owners in response to COVID-19 may prove to be excellent opportunities for expanding their customer base or modifying their retail strategy.

For results testing variables of education, income, and employment status, there is a general and consistent trend: individuals with higher education (i.e., a post-graduate degree compared with high school graduate and those with some education), a more affluent income, and workers (i.e., paid, self-employed), including those looking for work, tended to offer more actions towards small business at the onset of the pandemic. While this general trend aligns with previous literature indicating that education level and employment status influence consumers' level of resilience [63,84], it also adds an important indication of the type of individual who may be more inclined to seek small businesses as part of their shopping endeavors, helping small businesses to overcome challenges brought on by COVID-19. Small businesses tend to offer merchandise made in smaller batches [85], which tends to drive up the price of merchandise, compared with big box retailers who benefit from economies of scale [86]. Research has shown that consumers with higher levels of income and higher levels of education are less likely to experience negative financial impacts due to the COVID-19 crisis [87]. This research and the findings of this study offer direction to small business owners. To survive and perhaps even thrive during the pandemic, small businesses may shift part of their operations to focus on offering unique and high-quality products, with an elevated level of customer service to attract consumers with higher levels of income and encourage repeat loyalty behaviors enhancing business performance.

The limitations of this study present opportunities for future research. First, this study only investigated two research questions centered on consumers' emotional and cognitive experiences, as well as their demographics, and collected data at the onset of the COVID-19 pandemic. It is possible that additional consumer factors may have an impact on small businesses sustainability during the pandemic, e.g., consumer confidence levels or the severity of COVID-19 in one's community. Similarly, given the low values of $\mathrm{R}^{2}$ from the regression analysis with shopping frequency and the number of services used (12\% and $4 \%$, respectively) and the two dependent variables may not capture comprehensive consumer actions in times of a disaster, future research can benefit from examining different outcome variables such as the perceived threat of in-store infection [88]. Secondly, this study examined emotions experienced during a pandemic as an indicator of consumers' willingness to support local business. This broad conceptualization does not include a mediator or moderator, such as such as fears or stressors [32,38]. This is particularly noteworthy given that this research was collected at the beginning of the COVID-19 pandemic. As such, this research can serve as a springboard for future studies which might include the addition of mediators and/or moderating variables. Additionally, it is possible that consumption patterns may vary depending on whether an enterprise is micro, small, or medium. This article examined consumer behavior for local businesses at the start of the COVID-19 pandemic. The findings from this article offer valuable insight and a snapshot in time regarding consumer behavior at the start of the pandemic. While this study does not examine consumer behavior over an extended period of time, additional research conducted later in the pandemic has shown that some changes in consumer behavior are expected to remain consistent. Technology advances during the pandemic combined with changing consumer demographics and innovative consumer responses will continue to characterize consumer behavior beyond the pandemic [89]. In addition, although consumer behavior for small business during the pandemic implies that such sustainable consumption is likely to be conscious and deliberate action, no attention to this account was made in this study. Future research can advance the current understanding by identifying motivations and/or awareness that affect consumer sustainable consumption supporting small business as deliberate (vs. spontaneous) actions. 
Further research should continue to understand consumer sustainable consumption practices for small business by enterprise size and the counterparts or relative magnitude of cognitive vs. emotional factors that impact outcomes. Additionally, this research only surveyed consumers rather than small business owners. Future research should capture consumer sustainable consumption from business owners/managers to fully understand factors that enhance business operations. This study also utilized a convenience sampling method in data collection. For a greater representation of the United States population, probability sampling should be utilized. Last, it is recommended that future research examine small-business risk management and contingency planning from a diverse sample of business owners/managers (i.e., with varying degrees of success during the pandemic) and various types of community populations (i.e., rural/urban, varying degrees of community spread of COVID-19) to fully understand the factors that have an impact on small businesses during the pandemic.

Author Contributions: Conceptualization, M.C., S.H., C.T.S. and A.B.; methodology, S.H., M.C., C.T.S. and A.B.; formal analysis, S.H. and M.C.; investigation, S.H. and M.C.; resources, M.C. and S.H.; data curation, S.H.; writing, M.C., S.H., C.T.S. and A.B.; writing-original draft preparation, M.C. and S.H.; writing-review and editing, M.C., S.H., C.T.S. and A.B.; visualization, S.H. and M.C.; supervision, S.H.; project administration, M.C. All authors have read and agreed to the published version of the manuscript.

Funding: This research received no external funding.

Institutional Review Board Statement: The study was conducted according to the guidelines of the Declaration of Helsinki, and approved by the Institutional Review Board of The University of Tennessee UTK IRB-20-05802-XM on 6 April 2020.

Informed Consent Statement: Informed consent was obtained from all subjects involved in the study.

Data Availability Statement: The data presented in this study are available on request from the corresponding author.

Conflicts of Interest: The authors declare no conflict of interest.

\section{References}

1. Alexander, D.; Karger, E. Do Stay-at-Home Orders Cause People to Stay at Home? Effects of Stay-at-Home Orders on Consumer Behavior. Available online: https:/ / ssrn.com/abstract=3583625 (accessed on 11 September 2020).

2. Bartik, A.W.; Bertrand, M.; Cullen, Z.B.; Glaeser, E.L.; Luca, M.; Stanton, C.T. How Are Small Businesses Adjusting to COVID-19? Early Evidence from a Survey. Available online: https:/ / www.nber.org/papers/w26989 (accessed on 21 August 2020).

3. SBE Council. Facts and Data on Small Businesses and Entrepreneurship. Available online: https://sbecouncil.org/about-us/ facts-and-data / (accessed on 20 June 2020).

4. Accenture. How COVID-19 Will Permanently Change Consumer Behavior. Available online: https://www.accenture.com/ _acnmedia/PDF-123/Accenture-COVID19-Pulse-Survey-Research-PoV.pdf (accessed on 28 October 2021).

5. Sharma, G.D.; Thomas, A.; Paul, J. Reviving Tourism Industry Post-COVID-19: A Resilience-based Framework. Tour. Manag. Perspect. 2021, 37, 199786. [CrossRef] [PubMed]

6. Baker, S.R.; Farrokhnia, R.A.; Meyer, S.; Pagel, M.; Yannelis, C. How does Household Spending Respond to an Epidemic? Consumption during the 2020 COVID-19 Pandemic. Available online: https:/ / www.nber.org/papers/w26949 (accessed on 21 August 2020).

7. Islam, T.; Pitafi, H.; Wang, Y.; Aryaa, V.; Mubarik, S.; Akhater, N.; Xiaobei, L. Panic buying in the COVID-19 pandemic: A multi-country examination. J. Retail. Consum. Serv. 2021, 59, 102357. [CrossRef]

8. Laato, S.; Islam, A.N.; Farooq, A.; Dhir, A. Unusual purchasing behavior during the early stages of the COVID-19 pandemic: The stimulus-organism-response approach. J. Retail. Consum. Serv. 2020, 57, 102224. [CrossRef]

9. Naeem, M. Do social media platforms develop consumer panic buying during the fear of COVID-19 pandemic. J. Retail. Consum. Serv. 2020, 58, 102226. [CrossRef]

10. Prentice, C.; Chen, J.; Stantic, B. Timed intervention in COVID-19 and panic buying. J. Retail. Consum. Serv. 2020, 57, 102203. [CrossRef]

11. McDonald, S.; Oates, C.J.; Alevizou, P.J.; Young, C.W.; Hwang, K. Individual strategies for sustainable consumption. J. Mark. Manag. 2012, 28, 445-468. [CrossRef]

12. Roberts, J.A. Green consumers in the 1990s: Profile and implications for advertising. J. Bus. Res. 1996, 36, 217-231. [CrossRef]

13. Curtis, S.K.; Lehner, M. Defining the sharing economy for sustainability. Sustainability 2019, 11, 567. [CrossRef] 
14. Huang, M.-H.; Rust, R.T. Sustainability and consumption. J. Acad. Mark. Sci. 2011, 39, 40-54. [CrossRef]

15. Elkington, J. Cannibals with Forks: The Triple Bottom Line of 21st Century Business; Capstone Press Publication: Oxford, UK, 1997.

16. Lim, W.M. Inside the sustainable consumption theoretical toolbox: Critical concepts for sustainability, consumption, and marketing. J. Bus. Res. 2017, 78, 69-80. [CrossRef]

17. Gilg, A.; Barr, S.; Ford, N. Green consumption or sustainable lifestyles? Identifying the sustainable consumer. Future 2005, 37, 481-504. [CrossRef]

18. Humphries, J.E.; Neilson, C.; Ulyssea, G. The Evolving Impacts of COVID-19 on Small Businesses since the CARES Act. Available online: https: / / cowles.yale.edu/sites/default/files/files/pub/d22/d2230.pdf (accessed on 20 January 2021).

19. Seyfang, G. Ecological citizenship and sustainable consumption: Examining local organic food networks. J. Rural Stud. 2006, 21, 383-395. [CrossRef]

20. Yildiz, H.; Heitz-Spahn, S.; Belaud, L. Explaining small-retailer patronage through social capital theory. Int. J. Retail. Distrib. Manag. 2017, 45, 641-659. [CrossRef]

21. Parnell, J.A.; Lester, D.L.; Long, Z.; Köseoglu, M.A. How environmental uncertainty affects the link between business strategy and performance in SMEs: Evidence from China, Turkey, and the USA. Manag. Decis. 2012, 50, 546-568. [CrossRef]

22. Gaddum, R. Business continuity and disaster recovery in the retail sector. Int. J. Retail. Distrib. Manag. 2002, 30. [CrossRef]

23. Josephson, A.; Schrank, H.; Marshall, M. Assessing preparedness of small businesses for hurricane disasters: Analysis of pre-disaster owner, business and location characteristics. Int. J. Dis. Risk Reduct. 2017, 23, 25-35. [CrossRef]

24. Sahebjamnia, N.; Torabi, S.A.; Mansouri, S.A. Integrated business continuity and disaster recovery planning: Towards organizational resilience. Eur. J. Oper. Res. 2015, 242, 261-273. [CrossRef]

25. Zhang, Y.; Lindell, M.K.; Prater, C.S. Vulnerability of community businesses to environmental disasters. Disasters 2009, 33, 38-57. [CrossRef]

26. Cao, S.; Leung, D. Credit constraints and productivity of SMEs: Evidence from Canada. Econ. Model. 2020, 88, 163-180. [CrossRef]

27. FEMA. Protecting Your Business. Available online: https://www.fema.gov/protecting-your-businesses (accessed on 5 November 2020).

28. Amadeo, K. Hurricane Katrina Facts, Damage, and Costs: What Made Katrina So Devastating? Available online: https: / / www.thebalance.com/hurricane-katrina-facts-damage-and-economic-effects-3306023 (accessed on 15 April 2020).

29. Alesch, D.J.; Holly, J.N.; Mittler, E.; Nagy, R. Organizations at Risk: What Happens When Small Businesses and Not-for-Profits Encounter Natural Disasters? Available online: http://www.chamberofecocommerce.com/images/Organizations_at_Risk.pdf (accessed on 20 June 2020).

30. Asgary, A.; Anjum, M.I.; Azimi, N. Disaster recovery and business continuity after the 2010 flood in Pakistan: Case of small businesses. Int. J. Dis. Risk Reduct. 2021, 2, 46-56. [CrossRef]

31. Davis, T.E.; Grills-Taquechel, A.E.; Ollendick, T.H. The psychological impact from hurricane Katrina: Effects of displacement and trauma exposure on university students. Behav. Ther. 2010, 41, 340-349. [CrossRef]

32. Hackbarth, M.; Pavkov, T.; Wetchler, J.; Flannery, M. Natural disasters: An assessment of family resiliency following Hurricane Katrina. J. Marital Fam. Ther. 2012, 38, 340-351. [CrossRef]

33. Business Wire. New National Disaster Preparedness Poll Reveals Americans are More Concerned, Less Prepared for Future Crises. Available online: https:/ / www.businesswire.com/news/home/20200610005148/en/New-National-Disaster-PreparednessPoll-Reveals-Americans (accessed on 10 October 2020).

34. Addo, P.C.; Jiaming, F.; Kulbo, N.B.; Liangqiang, L. COVID-19: Fear appeal favoring purchase behavior towards personal protective equipment. Serv. Ind. J. 2020, 7-8, 471-490. [CrossRef]

35. Larson, L.R.; Shin, H. Fear during natural disaster: Its impact on perceptions of shopping convenience and shopping behavior. Serv. Mark. Q. 2018, 39, 293-309. [CrossRef]

36. Witte, K.; Allen, M. A meta-analysis of fear appeals: Implications for effective public health campaigns. Health Educ. Behav. 2000, 27, 591-615. [CrossRef] [PubMed]

37. Arndt, J.; Cook, A.; Routledge, C. The blueprint of terror management. In Handbook of Experimental Existential Psychology; Greenberg, J., Kool, S.L., Pyszczynski, T., Eds.; The Guilford Press: New York, NY, USA, 2004; pp. $35-53$.

38. Elmore, C. Irma: Frenzied Buying in Palm Beach, St. Lucie Regions Led State. Available online: https://www.palmbeachpost. com/article/20170915/BUSINESS/ 812028760 (accessed on 23 June 2020).

39. NRF. COVID-19 Upends How We Shop. Available online: https://nrf.com/blog/covid-19-upends-how-we-shop (accessed on 13 September 2020).

40. Shopkick. Majority of Americans are Change How They Shop due to COVID-19 Concerns. Available online: https:// www.shopkick.com/partners/blog/majority-of-americans-changing-how-they-shop-due-to-covid-19-concerns/ (accessed on 14 November 2020).

41. Lewis, D.; Mertens, K.; Stock, J.H. US Economic Activity during the Early Weeks of the SARS-CoV-2 Outbreak. Available online: https:/ / www.nber.org/papers / w26954 (accessed on 21 January 2021).

42. De Pelsmacker, P.; Driesen, L.; Rayp, G. Do consumers care about ethics? Willingness to pay for fair-trade coffee. J. Consum. Aff. 2005, 39, 363-385. [CrossRef]

43. Geissinger, A.; Laurell, C.; Öberg, C.; Sandström, C. How sustainable is the sharing economy? On the sustainability connotations of sharing economy platforms. J. Clean. Prod. 2019, 206, 419-429. [CrossRef] 
44. East, R.; Hammond, K.; Harris, P.; Lomax, W. First-store loyalty and retention. J. Mark. Manag. 2000, 16, 307-325. [CrossRef]

45. Hirogaki, M. Frequency of retail services, membership fee and real store shopping experience: Analysing consumer preference. Int. J. Bus. Glob. 2019, 23, 367-382. [CrossRef]

46. Mortimer, G.; Hasan, S.F.E.; Andrew, L.; Martin, J. Online grocery shopping: The impact of shopping frequency on perceived risk. Int. Rev. Retail. Distrib. Consum. Res. 2016, 26, 202-223. [CrossRef]

47. Verhoef, P.C.; Franses, P.H.; Hoekstra, J.C. The effect of relational constructs on customer referrals and number of services purchased from a multiservice provider: Does age of relationship matter? J. Acad. Mark. Sci. 2002, 30, 202-216. [CrossRef]

48. Smith, C.; Carlson, B.E. Stress, coping, and resilience in children and youth. Soc. Serv. Rev. 1997, 71, 231-256. [CrossRef]

49. Sneath, J.Z.; Lacey, R.; Kennett-Hensel, P.A. Coping with a natural disaster: Losses, emotions, and impulsive and compulsive buying. Mark. Lett. 2009, 20, 45-60. [CrossRef]

50. Ahmadi, F. Culture, Religion and Spirituality in Coping: The Example of Cancer Patients in Sweden; Acta Universitatis Upsaliensis: Upsala, Sweden, 2006.

51. Folkman, S. Stress: Appraisal and coping. In Encyclopedia of Behavioral Medicine; Gellman, M.D., Turner, J.R., Eds.; Springer: New York, NY, USA, 2013; pp. 1913-1915.

52. Lim, J.R.; Liu, B.F.; Egnoto, M.; Roberts, H.A. Individuals' religiosity and emotional coping in response to disasters. J. Conting. Crisis Manag. 2019, 27, 331-345. [CrossRef]

53. Choi, Y.; Lin, Y.H. Consumer responses to Mattel product re-calls posted on online bulletin boards: Exploring two types of emotion. J. Public Relat. Res. 2009, 21, 198-207. [CrossRef]

54. Jin, Y.; Pang, A.; Cameron, G.T. Toward a publics-driven, emotion-based conceptualization in crisis communication: Unearthing dominant emotions in multi-staged testing of the integrated crisis mapping (ICM) model. J. Public Relat. Res. 2012, 24, 266-298. [CrossRef]

55. Kim, H.J.; Cameron, G.T. Emotions matter in crisis: The role of anger and sadness in the publics' response to crisis news framing and corporate crisis response. Commun. Res. 2011, 38, 826-855. [CrossRef]

56. Bonnanno, G.A. Loss, trauma, and human resilience: How we underestimate the human capacity to thrive after extremely aversive events? Am. Psychol. 2004, 59, 20-28. [CrossRef]

57. Kimhi, S.; Eshel, Y.; Zysberg, L.; Hantman, S.; Enosh, G. Sense of coherence and socio-demographic characteristics predicting posttraumatic stress symptoms and recovery in the aftermath of the Second Lebanon War. Anx. Stress Coping 2010, 23, 139-152. [CrossRef]

58. Pfefferbaum, B.J.; Reissman, D.B.; Pfefferbaum, R.L.; Klomp, R.W.; Gurwitch, R.H. Building resilience to mass trauma events. In Handbook of Injury and Violence Prevention; Bonzon, L.S., Sleet, D.A., Mercy, J.A., Eds.; Springer: New York, NY, USA, 2008; pp. 347-358.

59. McKenna, F.P. It won't happen to me: Unrealistic optimism or illusion of control? Br. J. Psychol. 1993, 84, 39-50. [CrossRef]

60. Bronson, J.W.; Faircloth, J.B., III; Valentine, S.R. Business owners' optimism and business performance after a natural disaster. Psychol. Rep. 2006, 99, 960-962. [CrossRef] [PubMed]

61. Puri, M.; Robinson, D.T. Optimism and economic choice. J. Financ. Econ. 2007, 86, 71-99. [CrossRef]

62. Talwar, M.; Talwar, S.; Kaur, P.; Tripathy, N.; Dhir, A. Has financial attitude impacted the trading activity of retail investors during the COVID-19 pandemic? J. Retail. Consum. Serv. 2021, 58, 102341. [CrossRef]

63. Bonanno, G.A.; Galea, S.; Bucciarelli, A.; Vlahov, D. What predicts psychological resilience after disaster? The role of demographics, resources, and life stress. J. Consult. Clin. Psychol. 2007, 75, 671. [CrossRef] [PubMed]

64. Hirani, S.; Lasiuk, G.; Hegadoren, K. The intersection of gender and resilience. J. Psychiatr. Ment. Health 2016, $23,455-467$. [CrossRef]

65. Lightfoot, E.S.; Lesen, A.E.; Ferreira, R.J. Gender and resilience in Gulf Coast communities: Risk and protective factors following a technological disaster. Int. J. Dis. Risk Reduct. 2020, 50, 1-9. [CrossRef]

66. Moreno-Walton, L.; Koenig, K. Disaster resilience: Addressing gender disparities. World Med. Health Policy 2016, 8, 46-57. [CrossRef]

67. Enarson, E.; Fothergill, A.; Peek, L. Gender and disaster: Foundations and directions. In Handbook of Disaster Research; Rodríguez, H., Quarantelli, E.L., Dynes, R.R., Eds.; Springer: New York, NY, USA, 2007; pp. 130-146.

68. Cutter, S.L. The forgotten casualties redux: Women, children, and disaster risk. Glob. Environ. Chang. 2017, 42, 117-121. [CrossRef]

69. Kwan, C.; Walsh, C.A. Seniors' disaster resilience: A scoping review of the literature. Int. J. Dis. Risk Reduct. 2017, 25, 259-273. [CrossRef]

70. Eger, L.; Komárková, L.; Egerová, D.; Mičík, M. The effect of COVID-19 on consumer shopping behaviour: Generational cohort perspective. J. Retail. Consum. Serv. 2021, 61, 102542. [CrossRef]

71. Ferreira, R.J.; Cannon, C.; Buttell, F. COVID-19: Immediate predictors of individual resilience. Sustainability 2020, $12,6495$. [CrossRef]

72. McCaslin, S.E.; Jacobs, G.A.; Meyer, D.L.; Johnson-Jimenez, E.; Metzler, T.J.; Marmar, C.R. How does negative life change following disaster response impact distress among Red Cross responders? Prof. Psychol. Res. Pract. 2005, 36, 246-253. [CrossRef]

73. Kukihara, H.; Yamawaki, N.; Uchiyama, K.; Arai, S.; Horikawa, E. Trauma, depression, and resilience of earthquake/tsunami/nuclear disaster survivors of Hirono, Fukushima, Japan. Psychiatry Clin. Neurosci. 2014, 68, 524-533. [CrossRef] 
74. Maheswaran, D.; Meyers-Levy, J. The influence of message framing and issue involvement. J. Mark. Res. 1990, $27,361-367$. [CrossRef]

75. Smith, B.W.; Dalen, J.; Wiggins, K.; Tooley, E.; Christopher, P.; Bernard, J. The brief resilience scale: Assessing the ability to bounce back. Int. J. Behav. Med. 2008, 15, 194-200. [CrossRef]

76. Burnard, K.J.; Bhamra, R. Challenges for organizational resilience. Contin. Resil. Rev. 2019, 1, 17-25.

77. Fornell, C.; Larcker, D.F. Evaluating structural equation models with unobservable variables and measurement error. J. Market. Res. 1981, 18, 39-50. [CrossRef]

78. O'Brien, R.M. A caution regarding rules of thumb for variance inflation factors. Qual. Quant. 2007, 41, 673-690. [CrossRef]

79. US Department of Labor. COVID-19. Available online: https://www.osha.gov/SLTC/covid-19/background.html (accessed on 15 February 2021).

80. Naeem, M. Understanding the customer psychology of impulse buying during COVID-19 pandemic: Implications for retailers. Int. J. Retail. Distrib. Manag. 2021, 49, 377-393. [CrossRef]

81. Meza, A.K.T.; Freyre, J.R.A.; Cevallos, M.G.O.; Pico, M.J.M. Autonomy, good humor and support networks, potential of community resilience intervention in people victims of the earthquake in the Calderón Parish. Int. Res. J. Manag. IT Soc. Sci. 2018, 5,1-8. [CrossRef]

82. Panayiotou, G.; Panteli, M.; Leonidou, C. Coping with the invisible enemy: The role of emotion regulation and awareness in quality of life during the COVID-19 pandemic. J. Context. Behav. Sci. 2021, 19, 17-27. [CrossRef]

83. Accenture. COVID-19: How Consumer Behavior Will Be Changed. Available online: https://www.accenture.com/us-en/ insights / consumer-goods-services / coronavirus-consumer-behavior-research (accessed on 20 September 2020).

84. Ang, S.Y.; Uthaman, T.; Ayre, T.C.; Mordiffi, S.Z.; Ang, E.; Lopez, V. Association between demographics and resilience-a cross-sectional study among nurses in Singapore. Int. Nurs. Rev. 2018, 65, 459-466. [CrossRef] [PubMed]

85. Hastings, J. Local Retailers vs. Big Box: How Small Businesses Can Stay Competitive. Available online: https:// independentretailer.com/2020/02/04/local-retailers-vs-big-box-how-small-businesses-can-stay-competitive/ (accessed on 21 January 2021).

86. Armstrong, C.E. Small retailer strategies for battling the big boxes: A “Goliath" victory? J. Strategy Manag. 2012, 5, 41-56. [CrossRef]

87. O'Neill, B.; Gillen, M. Personal finance year end review. J. Financ. Plan. 2021, 34, 48-59.

88. Szymkowiak, A.; Gaczek, P.; Jeganathan, K.; Kulawik, P. The impact of emotions on shopping behavior during epidemic. What a business can do to protect customers. J. Consum. Behav. 2021, 20, 48-60. [CrossRef]

89. Donthu, N.; Gustafsson, A. Effects of COVID-19 on business and research. J. Bus. Res. 2021, 117, 284-289. [CrossRef] [PubMed] 